\section{Clinical and pathologic findings in hereditary spastic paraparesis with spastin mutation}

To the Editor: We read with interest the important article by White et al. ${ }^{1}$ on the pathologic findings in a patient who died with spastic paraplegic gene 4 (SPG4)-linked hereditary spastic paraparesis (HSP) and had a missense mutation in exon 10 of the SPAST gene. This report emphasizes the unique pathologic findings in this patient, who died of a dementing illness and brings to seven the number of families reported with late-onset dementia and HSP linked to chromosome $2 \mathrm{p} \cdot{ }^{1-4}$ This case is extremely important because it is the first to demonstrate the pathologic basis for dementia in SPG4-linked HSP. The findings reported in the article suggest a distinct pathologic process not seen in other dementing conditions. Earlier neuropsychological evidence of a unique dementing process in a large Irish family with HSP linked to SPG4 ${ }^{2}$ supports this thesis.

We differ from the authors in their interpretation of the data on the frequency of dementia in SPG4-linked HSP. They suggest that very few SPG4 families manifest this syndrome. Like many clinical phenomena, this disorder will only be found if one looks for it using appropriate clinical tools, including psychometric testing. We contend that cognitive impairment is an intrinsic feature of all families with SPG4-linked HSP. This can be demonstrated by using age-, sex-, and education-matched controls, and is evident from age 40 in such studies using the Cambridge Cognitive Examination (CAMCOG). After age 60 years, the CAMCOG scores for subjects with SPG4-linked HSP drops below 80 (the threshold for dementia), and after 70 years of age, patients show strikingly evident dementia with behavioral changes. ${ }^{4}$ This is clear in the study by White et al., ${ }^{1}$ as they mention that the index patient, as well as his sister and his mother, had memory impairment after age 70 years, according to reports of other family members.

The reason that this dementia has been so infrequently reported is because HSP is a rare disorder, and affected patients, who are often in wheelchairs, are protected by caregivers and not exposed to the usual challenges of new situations. In addition, neurologists have not systematically looked for this disorder. We would suggest that using the appropriate cognitive tests, deficits may be detected at least in the seventh decade of life. Perhaps a collaborative study between American and European clinicians with access to these families would be worthwhile.

P. Mc Monagle, MRCPI, P. Byrne, PhD, T. Burke, PhD, N. Parfrey, MD, M. Hutchinson, FRCP, Dublin, Ireland

Copyright $\odot 2001$ by AAN Enterprises, Inc.

\section{References}

1. White KD, Ince PG, Lusher M, et al. Clinical and pathologic findings in hereditary spastic paraparesis with spastin mutation. Neurology 2000; 55:89-94.

2. Webb S, Coleman D, Byrne P, et al. Autosomal dominant hereditary spastic paraparesis with cognitive loss linked to chromosome 2p. Brain 1998;121:601-609.

3. Heinzlef O, Paternotte C, Mahieux F, et al. Mapping of a complicated familial spastic paraplegia to locus SPG4 on chromosome 2p. J Med Genet 1998;35:89-93.

4. Byrne PC, Mc Monagle P, Webb S, Fitzgerald B, Parfrey N, Hutchinson M. Age-related cognitive decline in hereditary spastic paraparesis linked to chromosome 2p. Neurology 2000;54:1510-1517.

\section{Hypothermia and thermoregulatory derangements induced by valproic acid}

To the Editor: We read with interest the report of Zachariah et al. ${ }^{1}$ of four adults with hypothermia related to valproate therapy who improved dramatically on discontinuation of the drug and one patient who had severe heat intolerance improved with DVS.

We have seen a child who showed the same phenomenon. A 2 -year-old boy was admitted to the hospital after a prolonged febrile seizure that stopped only after several doses of benzodiazepines plus a phenobarbital load. In the past, he had a brief febrile convulsion. Neurodevelopmentally, he was intact. A CT scan showed a right arachnoid cyst (thought to be coincidental), and the EEG showed postictal change. He was prescribed valproate at $13 \mathrm{mg} / \mathrm{kg} /$ day and discharged.

Two days after discharge from the hospital on this dose, the boy was readmitted because his parents reported that the child's body temperature was constantly low, ranging from 33.8 to $34.5^{\circ} \mathrm{C}$ at home. They also noted that he was lethargic, irritable, and spoke with a lisp. They withheld the medication on the day of representation. Over the next 48 hours in the hospital, it was noted that his temperature was still low, with readings ranging from 34.7 to $36.5{ }^{\circ} \mathrm{C}$. The valproate was then discontinued. The child's temperature slowly returned to normal over the course of a week. His lethargy and speech disturbance improved within 48 hours of discontinuing valproate treatment.

We thought we should bring attention to the case of this child to highlight that children may also develop hypothermia with valproate therapy.

Lakshmi Nagarajan, FRACP, Kay Johnston, FRACP, Simon Williams, MBBS, Perth, Australia

Reply from the Authors: We appreciate the report of Nagarajan et al. of a 2-year-old boy who developed hypothermia, lethargy, and speech changes upon treatment of recurrent febrile convulsions with conventional dosages of valproate. Valproate is commonly used for a variety of seizure disorders in children, including recurrent febrile convulsions. ${ }^{2,3}$ We suspect that hypothermia is an unusual side effect of valproate therapy in children, as it seems to be in adults. Conversely, it seems possible that hypothermia does not attract clinical attention to the extent that fever does. In any case, it is probably reasonable to suggest that patients treated with valproate who develop hypothermia with lethargy or confusion should stop taking the drug before considering further diagnostic evaluation.

Jonathan T. Stewart, MD, Sally B. Zachariah, MD, Bay Pines, FL

Copyright @ 2001 by AAN Enterprises, Inc.

\section{References}

1. Zachariah SB, Zachariah A, Ananda R, Stewart JT. Hypothermia and thermoregulatory derangements induced by valproic acid. Neurology 2000;55:150-151.

2. Nordli DR, Pedley TA. Febrile seizures. In: Rowland LP, ed. Merritt's textbook of neurology. 9th ed. Baltimore, MD: Williams \& Wilkins, 1995 $869-870$

3. Bourrillon A. Treatment of febrile convulsions in infants. Arch Pediatrie 1995;2:796-798

\section{Cerebral ventricles are smaller in Hispanic than non-Hispanic patients with Alzheimer's disease}

To the Editor: We read with interest the study by Minagar et al., ${ }^{1}$ in which the authors reported that ventricular size was smaller in Hispanic than white non-Hispanic patients with $\mathrm{AD}$. We agree that studies investigating and comparing the different aspects of $\mathrm{AD}$ across ethnic groups are needed. We do not believe, however, that the classification of the two subgroups studied, Hispanic versus non-Hispanic white based on identification of ethnicity by the caregiver, was a proper one.

Ethnic classification may vary between members of different communities, especially if done by someone other than the participating patient him- or herself. As mentioned in another recent article, "what is black to someone from the United States may be white to a Brazilian or a Caribbean islander." Many examples can be given in which classification of ethnicity can be very difficult or misleading. The authors of a recent editorial, both of whom were of European descent but were born and raised in South American Spanish-speaking countries, mention that they would be probably classified as "Hispanic" in the United States, although neither is of Spanish descent. ${ }^{3}$ A partial solution to this problem, which has been proposed and used in several current reports, is that patients participating in population studies self-classify their ethnicity. ${ }^{4}$ Furthermore, instead of the use of such ill-defined terms as "Hispanic," mentioning a specific subgroup such as "Cuban," "Puerto- 
Rican," or "Native South American" could be much more informative for similar population studies, provided that there are no misunderstandings of the categories used. Even the term "white" or "non-Hispanic white" is too generalized; a Swedish person and a Greek person may both be called "Caucasian," but do they really belong to the same ethnic group?

Ethnicity as a variable in population studies is difficult to define and, therefore, its impact is hard to measure. More precise research methodology, perhaps based on genetic variables, could help to avoid inappropriate generalizations.

Jorge G. Burneo, MD, Nikolaos I.H. Papamitsakis, MD, Panayiotis D. Mitsias, MD, Detroit, MI

Reply from the Authors: We welcome the important comments by Burneo et al. regarding the difficulties involved in classifying individuals according to ethnicity. Their first point-that selfclassification of ethnicity is to be preferred in most situations-is well taken. However, many of our patients were too demented to provide self-classification, so we relied on their caregivers' classification as a reasonable alternative. We believe little was lost by this method because in most of our cases, the caregiver was an immediate family member of the same ethnicity and same country of origin.

Their second point, that the terms "Hispanic" and "white nonHispanic" are crude classifications that combine distinguishable subgroups, is an important one $\mathrm{e}^{5}$ and emphasizes the preliminary nature of our study. However, it is notable that a robust difference between groups was found even with the simple Hispanic versus white non-Hispanic dichotomous classification, indicating that at least some degree of commonality was present within each of the groups. Nevertheless, future work involving more finely delineated subgroups is certainly warranted.

Alireza Minagar, MD, Miami, FL

Copyright $\odot 2001$ by AAN Enterprises, Inc.

\section{References}

1. Minagar A, Sevush S, Bertran A. Cerebral ventricles are smaller in Hispanic than non-Hispanic patients with Alzheimer's disease. Neurology 2000;55:446-448.

2. Caldwell SH, Popenoe R. Perceptions and misperceptions of skin color. Ann Intern Med 1995;122:614-617.

3. Fustinoni O, Biller J. Ethnicity and stroke: beware of the fallacies. Stroke 2000;31:1013-1015.

4. Ethnicity, race and culture: guidelines for research, audit and publication. BMJ 1996;312:1094.

5. Sevush S, Peruyera G, Creaford F, Mullan M. Apolipoprotein-E epsilon 4 allele frequency and conferred risk for Cuban Americans with Alzheimer's disease. Am J Geriatr Psychiatry 2000;8:254-256.

\section{Using the electroretinogram to detect and monitor the retinal toxicity of anticonvulsants}

To the Editor: The editorial by Dr. Miller ${ }^{1}$ regarding the retinal toxicity of anticonvulsants is timely and informative. However, some clarification would be helpful. It appears that Dr. Miller is suggesting that patients taking any of the gamma-aminobutyric acid (GABA)-ergic antiepileptic drugs should have electroretinograms (ERG) before initiation of the drug and during the course of therapy. Although Dr. Miller states that preliminary data indicate that tiagabine has similar effects on the visual system as vigabatrin, no peer-reviewed references are provided. This is an important issue and before advocating ERG in patients taking tiagabine, it would be helpful to provide readers with documentation that tiagabine, which has a different mechanism of action than vigabatrin, can lead to retinal toxicity. Likewise, because many of the other commonly used antiepileptic drugs such as phenobarbital, divalproex sodium, benzodiazepines, felbamate, and topiramate have GABA-ergic effects, it is necessary to provide convincing evidence that the incidence of retinal toxicity is sufficiently high to justify routine ERG. Although Dr. Miller states that "further studies are needed to determine the optimum interval for monitoring the visual effects of other GABA-ergic drugs," the more relevant question is whether any monitoring is necessary at all.

Gregory L. Holmes, MD, Boston, MA
To the Editor: Dr. Miller ${ }^{1}$ recently noted the possibility that antiepileptic drugs other than vigabatrin, specifically tiagabine, might produce retinal damage. Dr. Miller is, however, a blinded investigator in a study of visual function during tiagabine treatment, which is sponsored by Abbott Laboratories (Abbott Park, IL). Our preliminary evidence shows that tiagabine does not cause visual abnormalities. Other findings support our results. Kalvianinen et al. ${ }^{2}$ reported no visual field defects in 15 patients treated with tiagabine monotherapy. Conversely, Beran et al. ${ }^{3}$ reported that six of 12 patients treated with tiagabine had visual field defects. These conflicting findings are important, but unpublished. I feel that these differences are due to methodologic problems that I encountered in a number of recent vigabatrin studies. Common problems with studies of visual function and antiepileptic drugs include the following:

1) They do not appropriately account for preexisting visual disturbances, and do not adequately screen abnormal test results due to cognitive impairment and poor test performance. Many patients with medically resistant epilepsy have cognitive impairment or visual abnormalities that are not associated with their medical therapies. We have benefited by having our results scrutinized by pharmaceutical company consultants. I am skeptical of the results of studies that do not address this issue. For example, a child was recently reported in Lancet with a "reversible" visual field defect after stopping vigabatrin. ${ }^{4}$ This case, however, probably demonstrates a test learning effect-we found that vigabatrin-associated field constrictions do not reverse. ${ }^{5}$

2) They use imprecise methods to analyze and compare various tests of vision. Most studies classify visual fields and ERG as "normal" or "abnormal," even though toxologic retinal effects range from mild to severe and can be quantified. Few studies employ control patients with epilepsy, and most rely on nonparametric statistics. Few studies validate abnormal ophthalmologic findings across various tests. We, for example, found strong associations between the results for the static fields, kinetic fields, and ERG amplitudes in vigabatrin-treated patients.

3) They assume that peripheral visual field loss is due to selective neurotoxic effects in the peripheral retina. Flash ERG and multifocal ERG show that vigabatrin affects both the central and peripheral retina. It is not surprising that diffuse drug toxicity partially spares central visual function, given the tenfold higher density of photoreceptors in the central retina compared to the peripheral retina.

Patients are often unaware of even major impairments in their vision, and so it is important that visual function be measured accurately in patients taking antiepileptic drugs to determine whether a neurotoxicologic effect is present. At this point, however, there is no evidence that GABA-ergic agents, as a class, produce retinal toxicity.

Gregory L. Krauss, MD, Baltimore, MD

Reply from the Author: I appreciate the opportunity to clarify the remarks I made concerning the known and potential effects of GABA-ergic drugs on the visual system. The only peer-reviewed articles on this subject of which I am aware concern vigabatrin. At the time I wrote my editorial, ${ }^{1}$ I was aware of the abstract by Beran et al., ${ }^{2}$ in which the authors stated that six of 12 patients taking tiagabine "had definite field defects similar to that [sic] seen with vigabatrin." It was my opinion that this information was sufficient to warrant a mention in the editorial, particularly when one compares the potential effects on quality of life from visual sensory deficits compared with the relative ease of monitoring visual function, clinically or electrophysiologically, in patients taking GABA-ergic drugs. Since this editorial was written, however, Sills et al. ${ }^{6}$ have shown that tiagabine does not accumulate in the retina of rats as does vigabatrin, and a number of investigators have concluded from unblinded studies that long-term use of tiagabine does not cause visual field defects or other visual sensory defects.,7-9 In addition, as noted by Dr. Krauss, our group at Johns Hopkins University Hospital is currently performing a clinical and electrophysiologic study of patients taking tiagabine versus control patients. I am performing the clinical assessments of these patients, and am blinded to which patients are taking 
tiagabine and which are not, as is Dr. Mary Johnson, who is performing the electrophysiologic studies. Although the study has not been completed, I can state that I have not been impressed with any visual sensory deficits in any of the patients I have examined, as I was during our studies of patients taking vigabatrin. ${ }^{5,10}$ Thus, although none of these studies, including our own, has yet been published as a peer-reviewed article, I do not believe that patients taking GABA-ergic drugs-other than vigabatrinrequire electrophysiologic monitoring, although there is no downside to monitoring such patients clinically.

Neil R. Miller, MD, Baltimore, $M D$

Copyright () 2001 by AAN Enterprises, Inc.

\section{References}

1. Miller NR. Using the electroretinogram to detect and monitor the retinal toxicity of anticonvulsants. Neurology 2000;55:333-334.

2. Kalviainen R, Nousiainen I, Mantyjarvi M, Riekkinen P. Absence of concentric visual field defects in patients with long-term tiagabine monotherapy. Neurology 1999;52(suppl 2):236.
3. Beran RG, Hung A, Plunkett M, Currie J, Sachinwalla T. Predictability of visual field defects in patients exposed to GABAergic agents, vigabatrin or tiagabine. Neurology 1999;52(suppl 2):A249.

4. Versino M, Veggiotti P. Reversibility of vigabatrin-induced visual-field defect. Lancet 1999;354:486.

5. Johnson MA, Krauss GL, Miller NR, Medura M, Paul SR. Visual function loss from vigabatrin: effect of stopping the drug. Neurology 2000; $55: 40-45$

6. Sills GJ, Patsalos PN, Butler E, et al. Concentration-related pharmacodynamic study of vigabatrin and tiagabine in rat brain and eye. Epilepsia 1999;40(suppl 7):244.

7. Fakhoury TA, Abou-Khalil B, Lavin P, et al. Lack of visual field defects with long-term use of tiagabine. Neurology 2000;54(suppl 3):A309.

8. Kalvianinen R, Salmenpera T, Jutila L, et al. Tiagabine monotherapy in chronic partial epilepsy. Epilepsia 1999;40(suppl 2):258.

9. Kalvianinen R, Nousiainen I, Mantyjarvi M. Absence of concentric visual field defects in patients with initial tiagabine monotherapy. Epilepsia 1999;40(suppl 2):259.

10. Miller NR, Johnson MA, Paul SR, et al. Visual dysfunction in patients receiving vigabatrin: clinical and electrophysiologic findings. Neurology 1999;53:2082-2087.

\section{Activate your online subscription}

At www.neurology.org, subscribers can now access the full text of the current issue of Neurology and back issues to 1995. Select the "Login instructions" link that is provided on the Help screen. Here you will be guided through a step-by-step activation process.
Neurology online offers:

- Access to journal content in both Adobe Acrobat PDF or HTML formats

- Links to PubMed

- Extensive search capabilities

- Complete online Information for Authors

- Examinations on designated articles for CME credit

- Access to in-depth supplementary scientific data 


\section{Neurology}

\section{Hypothermia and thermoregulatory derangements induced by valproic acid}

Lakshmi Nagarajan, Kay Johnston and Simon Williams

Neurology 2001;56;139

DOI 10.1212/WNL.56.1.139-a

\section{This information is current as of January 9, 2001}

\section{Updated Information \&} Services

References

Permissions \& Licensing

Reprints including high resolution figures, can be found at: http://n.neurology.org/content/56/1/139.2.full

This article cites 2 articles, 1 of which you can access for free at: http://n.neurology.org/content/56/1/139.2.full\#ref-list-1

Information about reproducing this article in parts (figures,tables) or in its entirety can be found online at:

http://www.neurology.org/about/about_the_journal\#permissions

Information about ordering reprints can be found online: http://n.neurology.org/subscribers/advertise

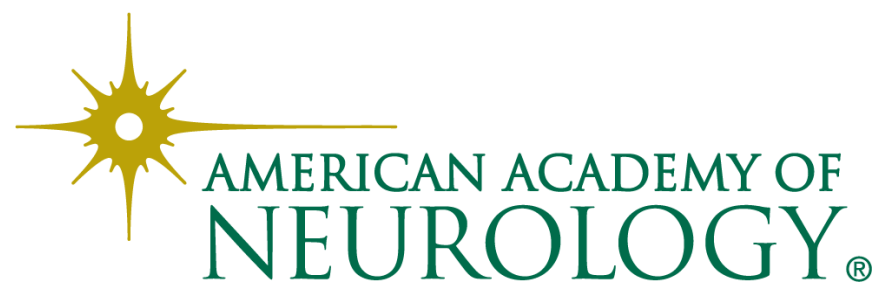

